\title{
ELECGIONES Y LECGIONES POÉTICAS DE JOSÉ EMILIO PACHECO (TERRAZAS, SOR JUANA, DARÍO, LUGONES Y VALLEJO)
}

La poesía del mexicano José Emilio Pacheco destacó desde sus inicios por reflexionar reiteradamente sobre la dilucidación del hecho poético. Si bien son numerosas las artes poéticas que podemos encontrar a lo largo de su trayectoria, éstas fueron más frecuentes en los años sesenta. Dada la importancia que cobra este corpus en la totalidad de su obra, la crítica se ha dedicado muchas veces a analizarlo, como también ha estudiado el uso recurrente de la intertextualidad, de los heterónimos, de sus filiaciones poéticas, su manera de abordar tópicos líricos como el tiempo, la degradación, la presencia de la ciudad, así como temáticas más recientes que él muy pronto incluyó en sus composiciones, como lo ecológico. Cierta resonancia crítica ha tenido lo que él mismo denominó "Aproximaciones", que son traducciones de poemas de otros escritores que Pacheco realiza de manera libre, pero que, en cualquier caso, se trata de composiciones escritas por autores que representan una referencia importante para el escritor mexicano. Como indica Luis Antonio de Villena: "elige sus traducciones por afinidad... Pudiéramos decir que son los poemas que Pacheco hubiera querido escribir, y que -en consecuencia- rehace. Se trata de lírica de su propia cuerda" ${ }^{1}$. Con estas traducciones se ampliaría -y nos amplía- su interpretación sobre lo poético, sobre lo metapoético en definitiva, aunque otras composiciones, aquellas en las que Pacheco homenajea a otros poetas, creemos deben formar parte de esa cosmovisión metapoética pachequiana. Unos homenajes que,

1 Luis Antonio de Villena, "Introducción”, José Emilio Pacheco, Júcar, Madrid, 1986, p. 86. 
de forma continua, han estado presentes en su obra y que, sin embargo, no han tenido todavía profundos análisis críticos, a pesar de su relevancia para entender de manera global sus implicaciones en la poesía de José Emilio Pacheco, pues existen indudables vínculos entre las artes poéticas y sus acercamientos -en parte deudas-a los poetas que homenajea. Consideramos, asimismo, que los poetas elegidos por José Emilio Pacheco son, entre otros motivos, un pretexto para explicar su propia poética y para mostrarnos su experiencia lectora y de escritura.

Para entender en toda su dimensión estos homenajes, conviene, aunque sea sucintamente, saber cuál es la visión de Pacheco sobre lo poético. A partir de No me preguntes cómo pasa el tiempo (1964-1968), su tercer poemario, y en el que por primera vez aparecieron sus homenajes a otros escritores, José Emilio Pacheco arremetió sin ningún rubor y con alevosía contra la concepción clásica de lo poético. Con gruesa ironía concluía que la poesía es fidedignamente efímera y que, a pesar de los espejismos con que los poetas pretenden dotarla, se encuentran ante la imposibilidad de enriquecerla. Igualmente, y dada la importancia que el tema de la temporalidad tiene en sus escritos, el verdadero valor de lo poético está en el ahora, en el presente, y no hay ninguna garantía de permanencia en el tiempo. En esta tesitura, tienen cabida también sus reflexiones sobre el cuestionamiento de la figura del poeta en la sociedad contemporánea. Como destacó Mario Benedetti:

Hay asimismo en Pacheco un recurrente cuestionamiento de su función como poeta y aun de la condición básica, insustituible de la poesía. Y todo ello expresado con tal sinceridad, que no despierta en el lector ni siquiera la mínima sospecha de que acaso se trata de una hábil máscara autocrítica².

En No me preguntes cómo pasa el tiempo, el poeta se convierte en un cirujano de la poesía, que es diseccionada por medio de múltiples "artes poéticas": "Crítica de la poesía", "Dichterliebe", "Job 18, 2", "Disertación sobre la consonancia", "Conversación romana" o "Legítima defensa", composición esta última en la que dictamina la incapacidad del creador para conseguir la supervivencia por medio de sus escritos. Estas propuestas conformarían por sí solas lo que José Miguel Oviedo ha denomina-

2 Mario Benedetti, "La poesía abierta de José Emilio Pacheco", en El ejercicio del criterio, Alfaguara, Madrid, 1995, p. 457. 
do "una urgencia por definir el oficio de poeta";; también aflora en sus versos la desmitificación del hecho poético: "debe plantearse a la asamblea una redefinición / que amplíe los límites (si aún existen los límites)" 4 . La poesía, ya fuera de toda ortodoxia, se concibe como un abanico infinito de posibilidades. En sus reflexiones, Pacheco incluye además cuestiones relacionadas con el proceso de creación del poema tal como podemos observar en "Crítica de la poesía". Mediante el uso de cursivas se destacan ejemplos de formulaciones que el autor presenta en un simulacro de acto creativo:

He aquí la lluvia idéntica y su airada maleza.

La sal, el mar deshecho...

Se borra lo anterior, se escribe luego:

Este convexo mar, sus migratorias

y arraigadas costumbres, ya sirvió alguna vez para hacer mil poemas

(p. 75).

Tanto en estas artes poéticas como en las que publicará años más tarde se detecta cierto escepticismo ante la idea de la eternidad del arte; sin embargo, en los homenajes a sus poetas de siempre, al ser convertidos en objeto del poema evidenciará su perdurabilidad, aunque también en esta actitud hay un propósito implícito: reavivar su legado.

Por las composiciones de José Emilio Pacheco transitarán -bien a modo de homenaje, de dedicatoria o de intertextualidad- poetas como Jorge Manrique, Lope de Vega, sor Juana Inés de la Cruz, Gustavo Adolfo Bécquer, Rilke, Juan Ramón Jiménez, Rubén Darío, Amado Nervo, Rafael Alberti, Efraín Huerta, Marco Antonio Montes de Oca, entre otros. Como ha señalado Selena Millares, nuestro autor:

establece una trama invisible de palabras, un diálogo sin tiempo con los poetas en el río único del canto, y se canaliza de este modo

3 José Miguel Oviedo, "José Emilio Pacheco: la poesía como ready made", Hispam, 1976, núm. 15, p. 273.

4 Tomamos como referencia la última edición de Tarde o temprano. (Poemas 1958-2009), Tusquets, Barcelona, 2010. En adelante, cuando se citen poemas o versos de esta edición, sólo anotaré el número de página. "Disertación sobre la consonancia" aparece en p. 79. En ocasiones, utilizaremos ediciones anteriores, porque existen variantes respecto a esta última; en ese caso, se señalará en nota. 
la necesidad del diálogo, de conjurar la orfandad del poeta abrumado por la tradición y por el desaliento. Se impone entonces la necesidad de profanar la poesía de los antecedentes, de arrasar las tumbas, quemar la tierra para repoblar, para renacer ${ }^{5}$.

Como veíamos en líneas precedentes, este corpus -el de aquellos poemas en los que un escritor y su legado son objeto de la poética pachequiana-, que José Emilio Pacheco ha ido desgranando a lo largo de su trayectoria, creemos que es axial porque se trata de otra forma de acceder a la metapoesía por medio de otras voces que el autor convierte, mediando la escritura, en propias. La lista sería extensa, como hemos indicado líneas más arriba, y es por ello que elegimos un corpus limitado, pero creemos que representativo, y que nos permitirá llegar a conclusiones que podrían asimismo aplicarse a aquellos poemas que no han sido incluidos en nuestra selección: se trata de poetas que no sólo son referenciales para el escritor mexicano, sino también para lectores habituales de poesía, lo que supone también una socialización de lo estético. Se hace necesario, entonces, ahondar en cómo José Emilio Pacheco se acerca, desde la poesía misma, a escritores fundamentales de la poesía latinoamericana como lo son, por diferentes motivos, Francisco de Terrazas, sor Juana Inés de la Cruz, Rubén Darío, Leopoldo Lugones y César Vallejo.

En estos homenajes, en esta íntima recuperación de su historia lectora, el autor elabora textos que podríamos calificar como herméticos por su actitud antirretórica y porque están desprovistos de cualquier anecdotismo. Se trata de una reconstrucción textual en la que no se descarta cierto carácter objetivo y en la que, al incorporar poetas de distintas épocas, la dimensión histórica se convierte en un tema: comprender al poeta, entenderlo en su paisaje vital. Por tanto, y a diferencia de otros poemas del autor en los que la materia textual trata la vida cotidiana o la trascendencia de la temporalidad que en ella se inmiscuye, en estos textos-homenaje el humus poético se construye con el material textual de otros que el poeta interioriza en su propia obra. Como fruto de esta experiencia, el poema resultante es la homogenización de la imagen que Pacheco tiene de esos otros que le antecedieron en la labor de la escritura. El autor evocado es sólo un punto de partida; no trata de descifrarlo, sino de

5 Selena Millares, "José Emilio Pacheco: apuntes para una poética", en De Vallejo a Gelman: un siglo de poetas para Hispanoamérica, Universidad, Alicante, 2011 (Cuadernos de América sin Nombre, 29), p. 215. 
encontrarlo mediante su propia voz. Esta peculiar reescritura de obras ajenas le permite actualizar las interpretaciones que sobre esos autores se han hecho, pero también, al exponerlos, Pacheco está incorporando elementos sociales en el discurso estético y abogando por la democratización de la belleza, aunque nunca entendida como utilitarismo hedonista, ni siquiera culturalista.

En los homenajes se establece, por tanto, una relación personal entre el propio autor y el poeta evocado, una correspondencia que en cualquier caso es ficticia, tanto como la poesía misma. Sin embargo, en esa ficción se trasluce también una verdad y ésta -aunque resulte paradójico- se establecería en la comunicación entre ambos poetas. En esta ficcionalización poética que Pacheco construye con sus escritores de siempre, la verosimilitud es máxima, ya que el escritor no comenta la poesía de los otros -como hemos señalado anteriormente- sino que su lenguaje, que enhebra su voz con otras voces, no necesariamente en un proceso intertextual, dice aquello con lo que el escritor homenajeado se sentiría cómplice. Así, Pacheco con sus versos evalúa y actualiza sus deudas con ellos ${ }^{6}$.

En un afán de corresponder a la temporalidad, analizaremos nuestro corpus desde los poetas más alejados en el tiempo a los más próximos. Trataremos de dilucidar cómo José Emilio Pacheco, en este tipo de textos, ubica a sus poetas en las coordenadas estéticas, históricas y culturales para destacar sus peculiaridades. De algún modo, en estos homenajes trata de construir su propia historia poética, pero también unir su voz a la de aquellos que brillantemente le precedieron.

Iniciamos con el poema titulado "Francisco de Terrazas", perteneciente a Islas a la deriva (1973-1975). Francisco de Terrazas, considerado el primer poeta novohispano, fue incluido en Flores de varia poesía (1577), así como recordado y elogiado por Miguel de Cervantes en La Galatea (1585). Unos versos suyos

${ }^{6}$ Carmen Dolores Carrillo Juárez apunta que: “Apropiarse de los textos de otros es una actitud fundamental que José Emilio Pacheco procura en su trabajo poético... trata de entender la propuesta y dialogar de alguna manera no tanto con el autor como en una tradición en la que se inscribe el texto" ("La poesía de José Emilio Pacheco y la tradición bíblica”, en José Emilio Pacheco: perspectivas críticas, coords. P. Popovic Karic y F. Chávez Pérez, Siglo XXI, México, 2006, p. 193). A este respecto, creemos que el escritor mexicano dialoga estrechamente con el autor y por supuesto también con la tradición, como trataremos de demostrar. 
serán rescatados por Pacheco en la entradilla de la tercera parte de "Las ruinas de México (Elegía del retorno)", que pertenece al poemario Miro la tierra (1984-1986): "Llorosa Nueva España que, deshecha, / te vas en llanto y duelo consumiendo..." (p. 318). Si volvemos al poema objeto de nuestro estudio, veremos cómo José Emilio Pacheco pondera la condición de Terrazas de haber sido "el primer hombre de una especie nueva", pues como apunta en el verso anterior, "Ni azteca, ni español: criollo, por tanto" (p. 172). Desde la perspectiva pachequiana, el primer hallazgo de Terrazas fue comprender, como hombre, la esencia de una nueva condición que pasará a convertirse en la identidad hispanoamericana. Y esa convicción de sentirse criollo lo capacitará para crear otra poesía, la de la nueva identidad. Pero insistimos: primero fue la intuición de sentirse otro - "Su primera pasión fue la extrañeza”, reza el verso inicial-, después vino la palabra poética renovada, pero esto fue consecuencia de lo anterior. Como ha afirmado Valeria Añón: "Francisco de Terrazas aparece retratado como el primero que, a partir de la palabra poética, intenta contestar la pregunta por la contradictoria identidad: «¿quién era en este mundo no europeo ni indio?»"

Francisco de Terrazas creó, por tanto, una poética que en sus manos dejó de ser española para convertirse en fundadora de la poesía latinoamericana, o al menos el comienzo de la literatura nacional: "fundó la otra poesía y escribió / el primer verso del primer soneto: / Dejad las hebras de oro ensortijado..." (p. 172). Y el poema termina con esa referencia intertextual, tan presente en la obra de José Emilio Pacheco, a la composición más conocida de Terrazas con la que aventajó a la que fue su modelo, el soneto de Camões "Tornai essa brancura a alva assucena". Sin duda, es una intertextualidad que actúa aquí como homenaje. Carmen Dolores Carrillo Juárez apuntó que la intertextualidad en Pacheco actúa en dos polos: el homenaje y la parodia, el poeta "se apropia de un texto con una actitud que oscila entre la gama de la continuidad a la subversión" ${ }^{8}$, pero quizás no tanto como "defamiliarización", tal como ha defendido María Rosa Olivera-Williams: "Los textos incorporados en sus poemas se despojan de su consistencia ideológica y el poema se convierte en un

7 VAleria AÑón, "Antigüedades mexicanas: memoria e intertextualidad en la poesía de José Emilio Pacheco”, Orbis Tertius, 2008, núm. 14, p. 9.

8 Carmen Dolores Carrillo JuÁrez, Espacio de confluencia. Intertextualidad y apropiación en la poesía de José Emilio Pacheco, tesis, El Colegio de México, México, 2008, p. 88. 
proceso productivo de defamiliarización del sujeto" ${ }^{\text {. Palabras }}$ que entrarían en contradicción con lo expresado en el poema "La desconstrucción de Sor Juana Inés de la Cruz" (pp. 422-423), composición sobre la que volveremos en líneas más adelante.

La composición "Francisco de Terrazas", por su contenido, conectaría con los versos de "Un poeta novohispano", poema incluido en el mismo libro y en el que Pacheco insiste en la esencia de lo nuevo en la poesía novohispana:

Sus poemas verdaderos en los que está su voz, los sonetos que alcanzan la maestría en el nuevo arte, a la sombra de Góngora, es verdad, pero con algo en ellos que no es enteramente español, los sembró noche a noche en la ceniza

La gran figura literaria del virreinato fue sor Juana Inés de la Cruz, a quien Pacheco le dedicará, con el título de "Sor Juana", un brevísimo poema, una sintética "metaforización" a modo de aforismo: "Es la llama trémula / en la noche de piedra del virreinato" (p. 174). El poema, al igual que el de "Francisco de Terrazas", está incluido en la segunda parte, de las cinco que componen Islas a la deriva, denominada por el autor "Antigüedades mexicanas".

En estos dos versos, creemos se hallan los grandes emblemas simbólicos de la obra de la escritora mexicana y, en parte también, los de José Emilio Pacheco. En palabras de Selena Millares: "El fuego es vida y movimiento, y es capaz de obrar el milagro de la redención. Y ese fuego es también la poesía, como en ese hermoso dístico dedicado a Juana de Asbaje"10; recordemos que el segundo libro poético del escritor se tituló El reposo del fuego (1963-1964).

Si Francisco de Terrazas fue el primer poeta novohispano y, por ello, nuestro escritor le rinde homenaje, sor Juana fue la última gran poetisa de los Siglos de Oro, la que logró sintetizar la portentosa literatura de aquella época. Así lo manifestó Pacheco en una conferencia que tuvo lugar en la Capilla Alfonsina de la Ciudad de México el 19 de octubre de 2010, tal como se indica en la siguiente nota de prensa de El Universal: "[José Emilio

9 María Rosa Olivera-Williams, "El monólogo dramático en la poesía de José Emilio Pacheco", RevIb, 174 (1996), p. 178.

10 Art. cit., p. 211. 
Pacheco] subrayó que a diferencia de otros vates de su época, Sor Juana aprendió de grandes plumas de los siglos XVI y XVII como Garcilaso de la Vega, Lope de Vega, Tirso de Molina y Calderón de la Barca, entre otros, y «los resumió a todos, y desde sincretismos paralelos extrajo su propia originalidad»"11. La frase pronunciada por nuestro autor dice mucho de la visión que defendió de lo poético. Baste recordar uno de los fragmentos de su discurso de recepción del Premio Iberoamericano de Poesía Pablo Neruda, en 2004, en el que habló del "don colonial o poscolonial de apropiarse de todo, de canibalizarlo todo, de ser literalmente amigo de lo ajeno para repartirlo entre nosotros los pobres -tan apartados del banquete europeo-, de hacer de la extrañeza y la amenidad algo íntimo y nuestro"12.

A partir de estas indicaciones, profundicemos en el sentido del poema que Pacheco dedica a sor Juana. El segundo verso, "en la noche de piedra del virreinato", podría ser interpretado como una referencia a la autoridad y a la dominación presentes en aquel tiempo: en medio de la opresión, de la oscuridad, de la cerrazón, ella logró prender la llama, la luz, la abertura, para incorporar de este modo el espacio histórico del que hablábamos en páginas anteriores. Pero esa "noche de piedra" podría ser también entendida como una sustitución o reelaboración de la "noche oscura", tan frecuentada por los místicos. Sin embargo, es posible otra exégesis si atendemos las siguientes palabras de Octavio Paz: "El fuego original y primordial, la sexualidad, levanta la llama roja del erotismo y ésta, a su vez, sostiene y alza otra llama, azul y trémula: la del amor. Erotismo y amor: la llama doble de la vida"13. Y es esa llama "azul y trémula" de la que nos habla Paz, la que también prendió sor Juana en sus poemas, es la llama trémula, la que hace que haya fuego en la poesía y que desde la poesía ese fuego se mantenga ${ }^{14}$.

11 Nota de prensa de El Universal. Disponible en internet en: www.eluniversal.com.mx/notas/717601.html [consultado el 30 de agosto de 2013].

${ }^{12}$ S. Millares, art. cit., p. 218.

13 Octavio Paz, La llama doble. Amor y erotismo, Seix Barral, Barcelona, 1993, p. 12.

14 VAleria AÑón (art. cit., p. 5) hace la siguiente interpretación del poema: "Por eso, presenta una definición -marcada por el presente indicativo del verbo «ser» ubicado en posición inicial- en la cual Sor Juana es retratada a partir de una metáfora («llama trémula») que conlleva su contraposición: la posibilidad de arder de modo temeroso, angustiado, sin consumirse por completo. Esta reunión de dos términos inesperados pone en escena tanto la racionalidad de la poeta como su pasión por el conocimiento implicada 
José Emilio Pacheco, prescindiendo del barroquismo que en ocasiones hacen gala los versos de la escritora, nos sumerge en una visión más que certera sobre el significado final de la obra de esta figura universal, que también será recordada en otro poema de Pacheco, en "La desconstrucción de Sor Juana Inés de la Cruz" (pp. 422-423), incluido en El silencio de la luna (1985-1996). Aquí, la poesía de sor Juana se erigirá como pretexto para lanzar una dura crítica al método desconstructivista mediante el cual -y estas palabras las toma el propio escritor de The Random House Dictionary para in troducirlas como entradilla al poema- "un texto no tiene referencias ni identificaciones estables, ya que esencialmente las palabras se refieren tan sólo a otras palabras y por tanto el lector debe aproximarse al texto eliminando todo concepto metafísico o etnocéntrico" (p. 422). En la primera parte del poema, con tono irónico, remite a la lectura de los textos de sor Juana que se hizo en un seminario desconstructivista. Pacheco se lamenta de algunas omisiones que, desde su punto de vista, son fundamentales para el entendimiento de cualquier poética: "Omitieron la historia (es triste siempre) / y las hipótesis biográficas", por ello: "Y los sonetos se vengaron y al fin/ desconstruyeron hasta el seminario" (p. 422). En la segunda parte de la composición, que actúa como cierre, José Emilio Pacheco acudirá al juego de palabras, ya presente en los versos aludidos de sor Juana ("Al que ingrato me deja, busco amante; / al que amante me sigue, dejo ingrata"), para enfatizar en la inexactitud en la que se puede incurrir al prescindir de la referencialidad. Y así dicen los versos de Pacheco: "Cuando lo dejó ingrata, la buscó amante. / Cuando lo siguió amante, la dejó ingrato. / Yllegaron al término preciso" (p. 423). Como ha advertido Valeria Añón, con la inclusión de estos versos finales, Pacheco usa algunos de sus recursos poéticos más reincidentes: "la oscilación presente-pasado, la posibilidad de leer el presente a partir del pasado, la intertextualidad, el trabajo con la cita y el montaje"15.

Deberíamos añadir que cada uno de los versos de Pacheco citados líneas más arriba presenta una estructura paralelística y, a su vez, los dos versos son paralelos. Se trata de un paralelismo antitético concentrado en los verbos (dejar / buscar / seguir)

en la imagen del fuego y ubicada temporalmente «en la noche de piedra del virreinato», término que enlazará este texto con los dos siguientes".

15 Art. cit., p. 8. 
y en los adjetivos (ingrata / amante). De verso a verso el paralelismo es sucesivo (dejar / buscar / seguir / dejar), lo que produce un efecto especular. Ese mismo efecto aparecía en los versos de sor Juana que José Emilio Pacheco apunta en nota a pie; recordémoslos: "Al que ingrato me deja, busco amante; / al que amante me sigue, dejo ingrata" (p. 423). Conviene destacar que, en el caso de sor Juana, la estructura refuerza su "especularidad" mediante el quiasmo presente en cada verso, inexistente en los de nuestro poeta.

En realidad, este poema no es en puridad un texto-homenaje, pero hemos creído que resultaría de interés examinarlo, porque la figura de sor Juana aparece en el poema como un pretexto para realizar una crítica a aquellos métodos de análisis que insisten en despojar las composiciones de sus referentes, que para nuestro autor son imprescindibles.

Otro poeta fundacional, Rubén Darío, ocupará un espacio esencial en las composiciones dedicadas a escritores, no sólo por el número de poemas en los que el nicaragüense es figura central, un total de seis, sino también por la diversidad a la hora de abarcar el intenso legado que dejó el autor de Azul. En 1999, Pacheco afirmó: "Darío se creyó Ariel pero era Calibán que canibalizó primero la literatura española y luego toda la literatura europea. Era la lengua española la que resucitaba con Darío. Cuanto se escribió en el siglo que termina hubiera sido imposible o inexplicable sin él. Su labor, escribió Borges en 1967, no ha cesado ni cesará"16.

Los seis poemas-homenaje a Rubén Darío están distribuidos en tres libros de Pacheco: "El centenario de Rubén Darío (19671916)" (p. 74) y "Nuevamente Darío" (p. 75) fueron incluidos en No me preguntes cómo pasa el tiempo (1964-1968); "Rubén Darío en el burdel" forma parte de La arena errante (1992-1998), y las otras tres composiciones restantes: "Una primera edición de Cantos de vida y esperanza (Rubén Darío, 1905)" (p. 702), "Un soneto atribuido a Salvador Díaz Mirón para elogiar a Darío y dolerse de no haberlo visto cuando pasó por Xalapa en 1910" (p. 702) y "De Rubén Darío a Francisco de Toledo. (A la manera de «Goya» en Cantos de vida y esperanza)" (p. 703) fueron ubicadas en el apartado IV, titulado "Celebraciones y homenajes", del libro Como la lluvia (2001-2008).

16 José Emilio Pacheco, "1899: Rubén Darío vuelve a España”, Letras Libres, México, junio de 1999, núm. 6. 
En uno de los poemarios más metapoéticos de José Emilio Pacheco, como lo es No me preguntes cómo pasa el tiempo, el padre del Modernismo será homenajeado de forma diversa, pero complementaria. En "El centenario de Rubén Darío (1967-1916)", al igual que en el poema dedicado a sor Juana, acude al aforismo: "Sólo el árbol tocado por el rayo / guarda el poder del fuego en su madera". El poema abarca la intensidad de un instante que tiene valor de eternidad, algo por otra parte habitual en la poética pachequiana, y que se acrecienta al utilizar una forma breve que ayuda a condensar su percepción sobre Darío. La composición, como hemos apuntado más arriba, guarda estrecha relación con la de sor Juana: si allí era la llama trémula la que hacía brotar el fuego en la poesía, y la poesía a su vez provocaba que ese fuego se mantuviese, aquí ese fuego poético sigue presente, pero ahora es el árbol tocado por el rayo el que se identifica metafóricamente con el poeta, de modo que sólo él es capaz de seguir alimentando este fuego. Ese árbol, además, nos remite a uno de los poemas más impresionantes de la obra dariana, que sirve como cierre de Cantos de vida y esperanza, "Lo fatal", y que comienza con el conocido verso: "Dichoso el árbol que es apenas sensitivo" 17 .

Sin embargo, el poema objeto de nuestro análisis ha sufrido una notable transformación desde las primeras ediciones de Tarde o temprano hasta la actual. En su origen, el poema constaba de treinta y dos versos y apareció con el título de "Declaración de Varadero" -así se mantendrá en las ediciones de 1980 y 1986-; los versos veintisiete y veintiocho coinciden exactamente con los del poema que aparece en la última edición, la del 2010. En la edición del 2000, a estos dos versos se añade un tercero que coincide con el veintinueve de la versión primigenia y que dice así: "y la fricción libera esa energía".

La composición fue escrita para el centenario del nacimiento de Darío y publicada en la revista Casa de las Américas de La Habana en 1967. El mexicano se sumó, junto con otros muchos poetas de la década de los años sesenta y anteriores, al homenaje que se hizo al nicaragüense desde la citada publicación ${ }^{18}$. En este caso, José Emilio Pacheco imaginará el sufrimiento del

17 Rubén Darío, Obra poética, ed. José Carlos Rovira con la colab. de Sergio Galindo, Biblioteca Castro-Fundación José Antonio de Castro, Madrid, 2011 , p. 471.

18 Véase Carmen Alemany Bay, "Versiones, revisiones y subversiones de la poesía de Rubén Darío en el siglo xx”, ALH, 36 (2007), 137-152. 
poeta de Azulal mostrar el final del movimiento que él mismo se encargó de encumbrar; además, referencias a Enrique González Martínez ${ }^{19}$ y a la propia poesía de Darío impregnarán el poema:

Cierra los ojos para verse muerto.

Comienza entonces la otra muerte, el agrio

batir las selvas de papel, torcerle el cuello

al cisne viejo como la elocuencia:

incendiar los castillos de hojarasca,

la tramoya retórica, el vestuario:

aquel desván llamado "modernismo" 20.

Nuestro poeta, al igual que aquellos que estuvieron a favor de una poética más directa, más coloquial, reivindicará al poeta íntimo, al trascendente, a aquel que supo liberarse de los anaqueles poéticos. Por ello, Pacheco cierra la composición diciendo que, a pesar de todo,

Pasaron, pues, cien años:

Ya podemos

perdonar a Darío

$$
\text { (p. 75). }
$$

Como anota Susana Zanetti, teniendo como referentes las primeras ediciones de este poema y la del año 2000:

Los cambios buscan la condensación liberada de detalles, como en general hace en todas las correcciones en la compilación de su obra. El texto de 1967, evidentemente una elegía ("En su principio está su fin. Y vuelve a Nicaragua / para encontrar la fuerza de la muerte" son sus versos iniciales), comenta la concepción dariana de la poesía y se distancia de su estética ("Las palabras / son imanes del polvo. / Los ritmos amarillos caen del árbol. / La música deserta / del caracol / y en su interior la tempestad dormida / se vuelve sonsonete o armonía / municipal y espesa, tan gastada / como el vals de latón...) ("Nosotros somos los efímeros")

19 Sobre este autor, José Emilio Pacheco ha dicho: "Cuando en 1911 Enrique González Martínez se hace eco de Verlaine para decirse a sí mismo «Tuércele el cuello al cisne», no reacciona contra el modernismo, como afirman tantos manuales: se despide de los elementos parnasianos y afirma los rasgos simbolistas", en "Prólogo" a Rubén Darío, Obras completas, ed. J. Ortega, Galaxia Gutenberg-Círculo de Lectores, Barcelona, 2007, t. 1, p. 31.

20 En esta ocasión, tomamos la referencia de Tarde o temprano, F.C.E., México, 1986, p. 74. 
pues "solo el árbol tocado por el rayo / guarda el poder del fuego en su madera / y la fricción libera esa energía"21.

Conviene en este punto señalar que José Emilio Pacheco pertenece a esa larga estirpe de poetas, como Lautréamont, Paul Valéry, Antonio Machado, Thomas S. Eliot, Octavio Paz, Juan Ramón Jiménez o Jorge Luis Borges que rechazan la idea de genialidad o de obra perfecta -entiéndase acabada-, idea que lo hace volver una y otra vez a la revisión de sus propios textos ${ }^{22}$. Estas correcciones le permiten, como él mismo ha dicho, "capitular ante la avasalladora imperfección" ${ }^{23}$ y, como afirmó en la primera edición de Tarde o temprano: "No acepto la idea de «texto definitivo». Mientras viva seguiré corrigiéndome"24. En las cuatro ediciones que hasta el momento se han publicado de Tarde o temprano -1980, 1986, 2000 y 2010-, se han reorganizado algunas secciones, se han suprimido otras, algunos poemas han cambiado de título, se han agregado poemas nuevos o han perdido parte de sus textos iniciales. Según Jorge Ruffinelli, "reescribir es, para Pacheco, des-cribir, aligerar el texto de todo aquello que no exprese. La expresión es eficaz por su economía, sin llegar al hermetismo de la escritura meramente simbólica, ni a negar su antípoda, la proliferación barroca"25; insistiendo en esta idea, Jorge Fernández Granados explica que "estos poemas no tienen forma definitiva porque son un producto del tiempo y en el tiempo. No se conciben pues como fin sino como proceso permanente" 26 .

La crítica a la fastuosidad y a la ostentación de la poética dariana resurgirán en los versos de Pacheco, y al padre del Modernismo se seguirá refiriendo -parafraseándolo e imitando

${ }^{21}$ Susana Zanetti, "Traducciones, versiones y homenajes en la poesía de José Emilio Pacheco”, Orbis Tertius, 2010, núm. 16, p. 10.

${ }^{22}$ Francisca Noguerol, "Leerse en Pacheco", introducción a Contraelegía de José Emilio Pacheco, Universidad de Salamanca-Patrimonio Nacional, Salamanca, 2009, p. 14.

23 José Emilio Pacheco, Ayer es nunca jamás, pról. José Miguel Oviedo, Monte Ávila, Caracas, 1978, p. 9.

24 Op. cit., p. 10.

25 Jorge Ruffinelli, "Al encuentro de la voz común: notas sobre el itinerario narrativo de José Emilio Pacheco", en La hoguera y el viento. José Emilio Pacheco ante la crítica, sel. y pról. de Hugo J. Verani, UNAM-Era, México, 1994, p. 174.

${ }^{26}$ Jorge Fernández Granados, "Prólogo" a José Emilio Pacheco, La fábula del tiempo, LOM Ediciones, Santiago de Chile, 2007, p. 18. 
la sonoridad de sus versos- en otro poema de No me preguntes cómo pasa el tiempo, "R.D. nuevamente", que en ediciones posteriores titulará "Nuevamente Darío". Una breve composición en la que no sólo se recupera el aire dariano, sino el símbolo modernista por excelencia, "el Cisne de ámbar y de nieve", dice:

Oscuridades del bajorrelieve,

figura maya,

y de repente,

como-una-flor-que-se desmaya

(tropo art nouveau y adolescente)

el Cisne de ámbar y de nieve

$$
\text { (p. 75). }
$$

El poema, creemos, rebosa sugerencias debido a los juegos internos que se intercalan entre los versos: esa flor que se desmaya es una reinterpretación de uno de los versos de la conocida "Sonatina" ("y en un vaso olvidada se desmaya una flor" ${ }^{27}$ ), una imagen que con anterioridad ya fue escrita por el poeta español Juan Arolas en Isaura: "Como flor que se desmaya / sin rocío de ventura / languidece la hermosura / nublando su triste faz". Sin embargo, en la composición de Pacheco, y en un afán de transgredir una imagen clásica, se contextualiza de otra forma, y las relaciones intertextuales se acentúan. Nuestro poeta establece un juego de rimas, no del todo usual en su poesía, entre "maya" y "desmaya", y quizá esa "figura maya" 28 no se refiera sólo a Darío, sino a una de las amantes de Zeus. No olvidemos que esa divinidad se convirtió en cisne para sus amantes, entre ellas Leda o Maia, y de esta última, la mayor de las pléyades, nació Hermes. Tras estas referencias se cierra el poema con el verso "el Cisne de ámbar y de nieve", que proviene de "Leda", perteneciente a Prosas profanas: "El cisne en la sombra parece de nieve; / su pico es de ámbar, del alba al trasluz" ${ }^{29}$. Un juego intertextual que en menor medida recuperará en un poema posterior, también dedicado al nicaragüense, titulado "Rubén Darío en el burdel", que se encuentra en La arena errante. Esta composición termina

27 RubÉn Darío, op. cit., p. 335.

28 En el poema, según Susana ZanetTi, Pacheco "apuesta por momentos de origen; por una parte, los mitos y cosmogonías mesoamericanos y la antigua palabra de los poetas; por otra la fundación de la poesía moderna por el modernismo, simbolizada por los textos darianos" (art. cit., p. 10).

29 Rubén Darío, op. cit., p. 447. 
con unos versos del poema XXIII de Cantos de vida y esperanza: "Pues la rosa sexual / al entreabrirse / conmueve todo lo que existe" (p. 456).

Como ya indicamos, hay otras tres composiciones en las que Rubén Darío se erige como protagonista: "Una primera edición de Cantos de vida y esperanza (Rubén Darío, 1905)", "Un soneto atribuido a Salvador Díaz Mirón para elogiar a Darío y dolerse de no haberlo visto cuando pasó por Xalapa en 1910" y "De Rubén Darío a Francisco de Toledo. (A la manera de "Goya» en Cantos de vida y esperanza)" que fueron ubicadas en el apartado IV, titulado "Celebraciones y homenajes" 30 , del libro Como la lluvia. Comencemos con esta observación de Susana Zanetti:

Si en Como la lluvia son pocas las referencias a otros poetas, habituales en los libros anteriores, vuelve, en el apartado IV, "Celebraciones y homenajes", a poner en escena el reconocimiento de un poeta a otro (al estilo de "Trébol" de Cantos de vida y esperanza), de Díaz Mirón a Darío, o de Darío a Francisco Toledo. Podríamos decir que son homenajes escritos "a la manera de", así como se vale de la epístola clásica en tercetos encadenados para la escritura de la que Lope de Vega dedica a Cervantes. Estas invocaciones se ciñen a los clásicos grecolatinos -Safo, Séneca, Propercio- y del Siglo de Oro español -Cervantes, Lope, Calderón, Quevedo- y en nuestro ámbito a Darío ${ }^{31}$.

En "Una primera edición de Cantos de vida y esperanza (Rubén Darío, 1905)", Pacheco crea un juego paronímico entre "hojas" y "ojos" desde el comienzo de la composición: "Hojas llenas de ojos", que se repetirá -ahora desde la incertidumbre- en el primer verso de la última estrofa: "Entre hojas y ojos circula -o no-". Lo interesante del poema, en cualquier caso, es la recuperación que nuestro poeta hace nuevamente del árbol, como veíamos en poemas anteriores: "El árbol / Desde el tocón reverdece

30 Para Susana Zanetti, Pacheco extrema "la compenetración entre ellos y el sujeto lírico cuando esa fraternidad lleva a éste a imitar su estilo, siguiendo, por una parte, esa amplia red de pasajes de la epístola clásica, de Horacio o de Petrarca, que ingresa a la poesía española con la epístola de Garcilaso a Boscán, y propicia su enorme cultivo en los Siglos de Oro. Por otra parte, la amplia red que cruza géneros -con la elegía y la sátira-, asuntos y lenguajes -el discurso moral, la amistad y el transcurrir cotidiano-, en estilo común, para pensar a la poesía como práctica y como teoría" ("Perduración de la poesía de José Emilio Pacheco”, Estudios, 2011, núm. 36, p. 51).

31 "Traducciones, versiones y homenajes...", p. 7. 
/ Cada vez que mueve sus páginas / El viento de otra mirada". Si el árbol reverdece, también cada una de las lecturas suponen un nuevo renacimiento de la obra de Darío; de ahí que en la siguiente estrofa escriba: "Mañana qué distinto / será leerlas / con otros ojos / hoy impensables todavía” (p. 702), lo que conectaría con lo expresado al final de "Declaración de Varadero"; recordémoslo: "Pasaron, pues, cien años: / Ya podemos / perdonar a Darío"32. De este modo, Pacheco establece una red intertextual entre la poesía de Darío y la suya al homenajear al mismo escritor.

En "Un soneto atribuido a Salvador Díaz Mirón para elogiar a Darío y dolerse de no haberlo visto cuando pasó por Xalapa en 1910", el escritor mexicano utiliza el recurso de la máscara ${ }^{33}$, tan habitual en su poesía, para atribuir la autoría a Díaz Mirón. Sin embargo, el vocabulario del poema es más afín a Darío que al poeta mexicano, como puede advertirse en el uso de palabras como armonía, perla o diamante, pintura y música, mundo arcano, melancolía u oro. En este supuesto homenaje ficcional de Díaz Mirón a Darío, que en realidad es de Pacheco a Darío, es fundamental el último terceto en el que se subraya la perpetuidad de la poesía sagrada: "Allí en costas de azur la muerte espera. / No tocará tus versos: son sagrados. / En ellos todo el año es primavera" (p. 703), carácter sagrado que para Pacheco se encuentra indudablemente en la poesía del nicaragüense.

En el último de los poemas del "Trébol", "De Rubén Darío a Francisco de Toledo. (A la manera de «Goya» en Cantos de vida y esperanza)", Pacheco, imaginariamente -como hace en algunas ocasiones-, pone en boca de Rubén Darío un poema dedicado a uno de los artistas plásticos vivos más importantes de México, Francisco Toledo. Pacheco utilizará el mismo tipo de estrofa que en el poema "A Goya", de Cantos de vida y esperanza, pero el vocabulario en este caso emparenta con la obra del artista mexicano, y asimismo se hace eco de los juegos de palabras presentes en el poema de Darío a Goya. En ocasiones, incluso, hay coincidencias con las rimas. En el poema "A Goya", Darío escribió: "Tu pincel asombra, hechiza, / ya en sus claros electriza, / ya en sus

32 Seguimos aquí la edición de 1986, op. cit., p. 75.

33 Son numerosos los artículos que hacen referencia al recurso de la máscara en la poesía pachequiana. Recordemos aquí uno de los más destacados: Lilvia Soto-Duggan, "Realidad de papel: máscaras y voces en la poesía de José Emilio Pacheco", en Ensayos críticos sobre poesía mexicana actual, eds. N. Klahn y J. Fernández, Katún, México, 1987, pp. 176-177. 
sombras sinfoniza" ${ }^{44}$; Pacheco dice: "Tu línea al mundo ironiza, / Canta a la vida en su liza / Perpetua con la ceniza" (p. 704). Si para Darío Goya era "Poderoso visionario, / raro ingenio temerario" (p. 460), para Pacheco, con la máscara de Darío, Toledo es "Pintor y mago y profeta, / Chamán, místico y poeta" (p. 704), lo que vendría a ser un Altazor de la pintura. El legado de Toledo es una "obra intensa y genial", como se nos dice en el primer verso de la última estrofa, y en eso Goya, Darío y Toledo se hermanan mediante un juego intertextual triple.

José Emilio Pacheco, y no sólo en estos poemas, es capaz de asumir la tradición literaria para filtrarla en su propio cedazo y de esa manera dar un nuevo impulso a lo literario. Un giro personal que unido al talento consigue una nueva regeneración del escritor al que hace referencia o, por lo menos, así lo intuimos en estos poemas dedicados al maestro del Modernismo.

Del modernista por excelencia pasa a otro poeta que se inició en este movimiento para prontamente ofrecernos una poesía nueva: el argentino Leopoldo Lugones. "Lugones a los ultraístas" fue incluido en su poemario Desde entonces (1975-1978):

$$
\begin{aligned}
& \text { Hablo una lengua muerta. } \\
& \text { Siento orgullo } \\
& \text { de que nadie me entienda } \\
& \text { (p. 219). }
\end{aligned}
$$

De nuevo un aforismo servirá para aumentar los conocimientos que José Emilio Pacheco tiene sobre escritores que son su referente. De manera global, estos versos nos remiten a un pensamiento recurrente en nuestro poeta a lo largo de su trayectoria, como es el tema de la erosión por el tiempo que actúa de manera extraordinaria en el carácter caduco de la escritura. Adentrándonos en el análisis de los versos, en el primero se alude a la lengua poética, lengua que en un amplio sentido es equiparable a lo que llamamos una lengua muerta. No hablamos de una lengua de uso, sino de una lengua sublime, como lo es también el conocimiento, pero ésta puede circular en ambientes poéticos; de ahí el orgullo. Al fin y al cabo lo que llamamos lenguas muertas son las que han supervivido y Lugones es, en este sentido, un superviviente. Sin embargo, creemos que el poema incluye una serie de referencias implícitas que tienen que 
ver con la historia cultural y literaria y que conciernen al autor de Lunario sentimental. Los ultraístas argentinos, especialmente los de la revista Martín Fierro, atacaron en más de una ocasión a este poeta sin estar conscientes de que fue paradigma y predecesor de la vanguardia en aquel país. José Emilio Pacheco insistirá en ello en más de una ocasión al afirmar que cuando Lugones publicó Lunario sentimental (1909) se convirtió en el "antipoeta" al marcar la frontera entre el Modernismo y las vanguardias $^{35}$. Estas reflexiones se ampliarán en otro escrito, en el que afirmaba que:

La vanguardia que rechazó la rima, en cambio recogió de Lugones su idea de que el verso vive de la metáfora ('la analogía pintoresca de las cosas entre sî́). A juicio de Lugones el lenguaje es un conjunto de imágenes, cada vocablo es una metáfora: hallar imágenes nuevas, expresarlas con claridad significa enriquecer y renovar el idioma ${ }^{36}$.

Sin embargo, la corta perspectiva temporal que los martinfierristas tuvieron no les permitió comprender que la poesía de su compatriota poseía algunos de los logros que ellos pretendían. Los martinfierristas, en sus ataques, no atendieron tanto a la poética del escritor, sino a las opiniones que éste tenía sobre la lengua. No olvidemos que los ultraístas de Martín Fierro pretendieron inventar una lengua que tenía como base el lunfardo y que con los años los hablantes del español no lograríamos entender. A este respecto, Lugones fue tajante: "emplear un idioma bastardo sólo porque es de acá, equivale a incomunicarse en la fealdad y en la pequeñez", para añadir que sería una "calamidad" hablar en un idioma argentino. Para él, lo patriótico era defender la castidad del lenguaje y en eso debían influir las personas cultas, "nada de incorporar las voces del pueblo"; para ello, "cuanto más genuino sea nuestro castellano, mejor nos entenderemos con la gente que habla", como apuntó en el "Prólogo" al Diccionario etimológico del castellano usual ${ }^{37}$.

35 José Emilio Pacheco, Poesía modernista. Una antología general, SEPUNAM, México, 1982, p. 475.

36 José Emilio Pacheco, "París era un desierto", Proceso, 19 de septiembre de 1987, núm. 567, p. 53.

37 Leopoldo Lugones, "Prólogo" al Diccionario etimológico del castellano usual, Academia Argentina de las Letras, Buenos Aires, 1944, p. 16. 
A pesar de todo, la voz que Pacheco otorga a Lugones se vanagloria, en legítima defensa, de ser un vestigio del pasado, pero desde la perspectiva pachequiana ser pasado es algo intrínseco a la poesía, aunque también es su obligación actuar como un ser vivo, renovarse. De alguna manera, esta composición conectaría con otras en las que el mexicano habla de la rápida decadencia de los estilos y los gustos de cada época histórica, como por ejemplo se puede leer en una composición dedicada a otro poeta: "Una cartita rosa a Amado Nervo", incluida en Irás y no volverás $(1969-1972)^{38}$.

Terminaremos las menciones a los homenajeados con otro grande de la poesía hispanoamericana, César Vallejo, a quien Pacheco ha dedicado tres poemas: "Birds in the night (Vallejo y Cernuda se encuentran en Lima)" y "De sobremesa, a solas, leo a Vallejo", ambos pertenecientes a Irás y no volverás, e incluidos en la quinta sección del citado libro que aparece encabezada por el conocido verso vallejiano "Considerando en frío, imparcialmente", el primero de una de las composiciones de Poemas humanos. El tercer poema, "César Vallejo", forma parte del libro Ciudad de la memoria (1986-1989). Si atendemos las palabras de Selena Millares, lo que hermana a ambos poetas es "la obsesión por la miseria, la materia ósea, la fatalidad" 39 .

En la primera composición, Pacheco fuerza imaginariamente el encuentro de dos de sus poetas referentes -como también ha hecho en otras ocasiones; por ejemplo en la composición titulada "Bécquer y Rilke se encuentran en Sevilla" (p. 372). El poema, en cualquier caso, no puede entenderse en toda su dimensión si no atendemos la primera parte del enunciado del título "Birds in the night". Este título procede de un poema de Verlaine (sólo como anécdota conviene recordar que procede de una nana de corte amoroso que se hizo popular en Londres a mediados del siglo XIX), en el que critica a las autoridades por su hipocresía, por reprender el amor homosexual entre él y el joven Rimbaud. A su vez, Luis Cernuda, tomando el mismo título, escribió un poema incluido en Desolación de la quime$\mathrm{ra}$, en el que tenía como referentes a ambos poetas franceses, $\mathrm{e}$ insiste de nuevo en la falsedad de la sociedad ante tales temas:

38 Así reza el poema: "Lo cursi es la elocuencia que se gasta. / No te preocupes / si sonreímos con tus versos dolientes / y nos sentimos hoy por hoy superiores. // Tarde o temprano / vamos a hacerte compañía” (p. 153).

39 Art. cit., p. 215. 
la falsedad con la que la sociedad trata a los poetas sublimes ya fallecidos será la temática de la composición. Por su parte, Pacheco, que actúa en esta ocasión como sujeto poético, desde Lima -aunque también establece comparaciones con Méxicorecuerda cómo por aquellas calles de la capital peruana César Vallejo anduvo, y allí escribió versos y "En vida lo patearon, lo escupieron, / lo mataron de hambre y de tristeza", pero "Ahora sí lo imitan, lo veneran / y es «un orgullo para el continente»". En ese encuentro imaginario, que lógicamente sólo actúa en la mente de Pacheco, Cernuda irrumpe en el poema: "Dijo Cernuda que ningún país / ha soportado a sus poetas vivos". A pesar de las miserias, las desdichas y el escaso reconocimiento literario que tuvo que sufrir el autor de Trilce a lo largo de su vida, surge la ironía pachequiana y termina el poema con cargada ironía: "Pero está bien así: / ¿No es peor destino / ser el Poeta Nacional / a quien saludan todos en la calle?" (p. 157). Esta idea del poeta maltratado por una sociedad en la que se prescinde de lo humanístico tendrá presencia en otro de los poemas incluidos en este mismo libro, en "Vidas de los poetas": "En la poesía no hay final feliz. / Los poetas acaban / viviendo su locura. / Y son descuartizados como reses / (sucedió con Darío)" (p. 150).

Más inquietante es el siguiente poema que comienza con el verso "En el pan huroneado por las hormigas". En un intento interpretativo del verso, podemos encontrar relaciones entre éste y la poesía vallejiana e incluso llegar a la conclusión, precipitada en este caso, de que ahí está la referencia al poema de Vallejo, "El pan nuestro", o establecer relaciones con la composición que da título a Los heraldos negros en la que también aparece este alimento esencial. Si avanzamos en la lectura del poema las sorpresas se multiplican. Pacheco habla de cómo las hormigas, tan caras poéticamente a nuestro escritor, van con paciencia devorando todo aquello que encuentran: "Las silenciosas ciegas van disciplinando / menudamente/ la continua erosión del mundo”. En esta ocasión, el poeta Vallejo es sólo un pretexto para Pacheco, y la lectura de sus poemas en la sobremesa es el quid por el cual puede regresar como siempre a una de sus obsesiones: la destrucción del mundo. Sólo cierta inquietud de corte vallejiano se trasluce en los últimos versos: "Como ellas / hemos perdido el habla / y es bajo cuerda el acabose" (p. 158).

El tercer poema, "César Vallejo", tiene evidentes relaciones intertextuales con el primero que dedicó al vate peruano. El sujeto poético, Pacheco, se encuentra nuevamente en Lima: 
"Por la ventana / entra el aire de Lima" (p. 359), y establece comparaciones entre la ciudad peruana y su ciudad natal; sin embargo, en aquel poema era la miseria la que unía a ambas ciudades: "Aquí por estas calles de miseria / (tan semejante a México)" (p. 157); ahora es la condición marítima o no: "Aquí sucumbe de mal de mar el nativo / de tierra adentro, de ciudades altas, / secas o muertas. / México en el páramo / que fue bosque y laguna / y hoy es terror y quién sabe" (p. 359). Es la circunstancia del sujeto poético, ahora en Lima, que sufre "mal de mar" por ser "de tierra adentro", lo que finalmente hace que recuerde a Vallejo en el cincuenta aniversario de su muerte: "En este viernes / 15 de abril, / a medio siglo / de que murió Vallejo" (p. 360), y el poema concluye con el verso "-y uno habla y habla", como dando a entender que ante el impresionante legado que el poeta peruano ha dejado todo lo demás son palabras que resultan huecas.

Sírvanos como colofón de este recorrido la composición "Contra Harold Bloom", que se encuentran en La arena errante (1992-1998), en la que el escritor mexicano responderá, ante "la angustia de las influencias", en la que tanto insistió el padre del canon, de la siguiente manera: "no podría escribir ni sabría que hacer / en el caso imposible de que no existieran / Zozobra, Muerte sin fin, Piedra de sol, Recuento de poemas" (p. 602). Gracias a López Velarde, a Gorostiza, a Paz, a Sabines, que son los autores que escribieron cada una de las obras citadas en el poema, pero también gracias a tantos otros poetas aquí mencionados y aquellos otros que nuestro poeta recordó en sus composiciones, se ha forjado la voz de José Emilio Pacheco, una voz que sin disimulo, e incluso alentando a ello, forja la suya propia en un acto de disidencia y subversión, palabras estas que caracterizarían gran parte de su obra poética.

Carmen Alemany Bay Universidad de Alicante 
